\title{
Simulation study for comparison of control structures for BFB biomass boiler
}

\author{
Milan Zlatkovikj Valentina Zaccaria Ioanna Aslanidou Konstantinos Kyprianidis \\ School of Business, Society and Engineering, Malardalen University, Vasteras, Sweden \\ \{milan.zlatkovikj, valentina.zaccaria, ioanna.aslanidou, \\ Konstantinos.kyprianidis\} @mdh. se
}

\begin{abstract}
Biomass fired boilers usage is increasing due to supportive policies and economic trends. Fluidized bed technology is identified as proper solution for lower quality fuels such as biomass. Moisture and heating value can vary significantly in biomass fuels. Without real-time information on their variation, they are a disturbance to the system. These disturbances affect the system steady state and decrease operational efficiency. Proper characterization of the disturbance enables the use of Feed-Forward control. Feed-Forward makes use of the knowledge about the updated condition of the fuel and can act towards reducing the impact of the fuel on offsetting the system. Feed-Forward Model Predictive Control is proposed as new control strategy. Comparison is made between the existing control strategy and the new proposed solution. Control performance is evaluated on three process outputs, in three different scenarios. Adding feed-forward signal for fuel moisture improves control performance in both controllers, while ultimately Feed-Forward Model Predictive Control shows the best performance in most comparison metrics.
\end{abstract}

Keywords: biomass fuel, fuel moisture, model predictive control, feed-forward, plant control

\section{Introduction}

Biomass usage as a fuel is constantly growing due to supportive government policies and positive market trends. The highest share of biomass utilization as fuel goes in combustion in large scale steam boilers, used in Combined Heat and Power (CHP) plants (Atsonios et al., 2020).

Fluidization technology has been implemented towards creating more favorable combustion conditions in the furnace (Leckner, 2003). Bubbling Fluidized Bed (BFB) and Circulating Fluidized Bed (CFB) boilers operate on this technology. CFB are the newer, improved version of the two, and therefore are more applied and more work is done on their analysis. However, for applications with lower power output, BFB boilers are still applicable and competitive (Peña, 2011). The differences between BFB and CFB boilers are in the power output, geometry of furnace, layout (configuration of heat exchangers), values of operational parameters, and there are differences in flow streams (mostly noted in the recirculation part) (Peña, 2011). Except for the main operational differences, there are noted differences in the research work done, such as analyzing the capability of power output change over time, temperature profiles in the furnace, and thermal capacity of the systems (Huttunen et al., 2017; Arena et al.,1995).

Process modeling is a cost-effective way to analyze system performance, compared to real tests at operating large scale facilities. The key requirement before process modeling is to specify the aim of the modeling work, since there are plenty of different types of models, and just the right combination of model and application can help towards effective process analysis (Atsonios et al., 2020). Simplified mass and energy balances models, with 0 dimensionality (e.g. divided in several control volumes of interest), are a simple and effective way for boiler system analysis (Sandberg et al., 2011). Although they provide less details compared to CFD and other high dimensional models that include more process features, their simulation time is shorter than CFD models and they can capture the process behaviors and be utilized e.g. for control or optimization purpose. Models that can be simulated much faster than real-time can be implemented on-line, as a prediction support for the controller (Szentannai, 2011; Zimmerman et al., 2018).

Most of the applied controllers in thermal power plant are based on Proportional Integral (PI) algorithm (Szentannai, 2011). This type of control is proven in operation and reliable. However, with the new demands for the power plants flexibility due to the rise of use of intermittent renewable energy sources, the current control structure efficiency is limited. PI controllers are known for their limitations for multi-input multi-output (MIMO) processes with strong coupling between variables, such as steam boilers (Szentannai, 2011).

On the other hand, Model Predictive Control (MPC) is perceived as a good option for replacement of the current controllers, improving control performance in strongly coupled systems (Qin and Badgewell, 2013). They are proven in applications in the chemistry industry, while their application in power plants is lagging behind (Szentannai, 2015). One of the main 
identified difficulties towards implementation of MPC is the deficit of quality dynamic models, on which the controller is based (Atsonios et al., 2020). In MPC, the controller relies on the accuracy of the underlying model. In particular, the performance can degrade in presence of unmodeled disturbances. Fuel quality (heating value and moisture) is the strongest disturbance in biomass combustion systems.

The necessity for increase of research work on dynamic modeling of biomass energy applications has been emphasized in a recent review (Atsonios et al., 2020). The amount of work published on this topic is scarce compared both to dynamic studies on fossil fuel systems and steady operation studies on biomass. In addition to this, many research groups develop separate models on sub-systems of the boiler, which does not allow for full system analysis and communication between different types of models used.

Combustion analysis on BFB boilers with biomass and waste fuels have been analyzed in (Ravelli et al., 2008; Galgano et al., 2005; Scala and Chirone, 2004). These models provide detailed analysis of the combustion process. However, they are too computationally demanding for implementation in control purposes.

Control work focusing on the water/steam side dynamics has been studied in (Åström and Bell, 2000). In this work, the combustion part of the boiler is simplified.

As mentioned above, modeling the disturbance to the process can enhance the control. The major uncertainty in the boiler is related to the heat input, which comes from fuel moisture variations. By having a model that includes information about the moisture variation in the incoming fuel, we have additional important parameter knowledge, which can help toward a better analysis of the system. The benefits of adding feed-forward signal to MPC controller are analyzed in (Carrasco and Goodwin, 2011). Combining the knowledge of the fuel moisture with advanced control method can help towards decreasing the effect of fuel variation on the process outputs.

The aim of this work is therefore to show how MPC can be applied in biomass-fueled BFB boilers, how it compares to conventional PI control, and quantify the benefit introduced by feed-forward (FF). In the following sections, the analyzed process and its characteristics are described, an overview of the numerical model and the control structures are given, after which results are presented and discussed.

\section{Process description}

The analyzed system is a Bubbling Fluidized Bed (BFB) Boiler fired by mix of woody fuels (bark, chips). It is used in Eskilstuna Strängnäs Energi och Miljö $\mathrm{AB}$ (ESEM), CHP plant, to provide electricity and district heating for the local municipality.
Its nominal operation parameters are listed in Table 1. Throughout the year the plant operates with change of the load (boiler power output) based on demand and plant condition. The boiler layout is presented in Figure 1. The boiler consists of a fluidized bed region, freeboard, a superheaters section $(\mathrm{SH} \mathrm{1,2,3)}$ and an cconomizer.

Table 1. Boiler nominal parameters

\begin{tabular}{|c|c|}
\hline Parameters & Value \\
\hline Boiler power output & $110 \mathrm{MW}$ \\
\hline Final Steam Temperature & $540^{\circ} \mathrm{C}$ \\
\hline Fuel Flow & $13.7 \mathrm{~kg} / \mathrm{s}$ \\
\hline Steam flow & $41.1 \mathrm{~kg} / \mathrm{s}$ \\
\hline Fuel LHV, wet basis & $8500 \mathrm{~kJ} / \mathrm{kg}$ \\
\hline Fuel moisture & $48 \%$ \\
\hline
\end{tabular}

The fuel is delivered into the fluidized bed region. In BFB boilers, a staged combustion is applied, where air is delivered at three different heights - primary, secondary and tertiary air. In addition, there is recirculation of flue gasses, which is used for temperature regulation in the fluidized bed region. Combustion process is completed along the freeboard, and after that, the hot flue gasses transfer the heat to the water/steam side, at the steam superheaters and the economizer.

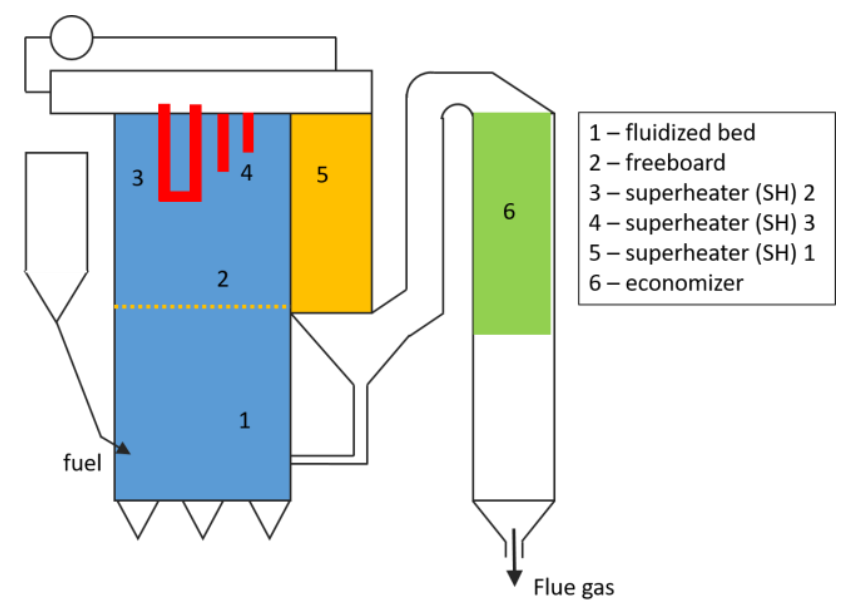

Figure 1. Boiler Layout

Water is pumped from the water tank, goes for preheating in the economizer, evaporates to steam in the evaporator pipes placed around the furnace and finally is superheated in 3 superheaters before entering the steam turbine. There are 2 steam attemperators (water sprays injected in the steam), to control steam temperature.

\section{Methodology}

\subsection{Model description}

Developing models for big industrial plants, such as steam boilers is a time demanding task. Given that 
boilers are extensively used for various applications and the effort to develop models of these plants, it is important to make sure of the model's reusability (Casella et al., 2014). Models developed with acausal approach allow for reusability with less effort compared to making a new one from scratch (Casella et al., 2014).

The programming language Modelica and the software Dymola are used in this work for that aim. With minor adjustments, the model can be used to simulate different system types and configurations. In addition, the model can be exported to various other software, to develop control or other frameworks. In this work, the Dymola model is exported to Simulink, where system identification (SI) and controller design are performed.

\subsection{Boiler equations}

Based on the Boiler layout, the system is divided in control volumes to describe the process characteristics in a simplified way and to capture all essential aspects of the process.

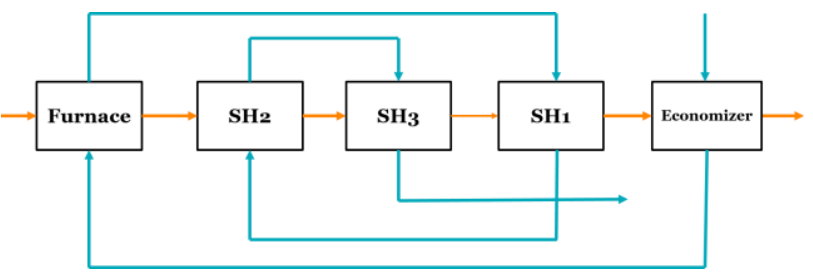

Figure 2. Boiler flows logics

The logic of the flows analyzed within the model is shown in Figure 2. Orange lines represent the path of the hot side (flue gas) and the blue lines represent the cold side (water/steam).

$$
\begin{gathered}
\Delta T=\frac{\left(T_{h 1}-T_{c 2}\right)-\left(T_{h 2}-T_{c 1}\right)}{\ln \left(\frac{T_{h 1}-T_{c 2}}{T_{h 2}-T_{c 1}}\right)}[K] \\
\frac{d T}{d t}=\frac{Q_{\text {balance }}}{H E_{\text {capacity }}}=\frac{Q_{\text {in }}-Q_{\text {out }}}{c p * m} \\
=\frac{Q_{\text {in }}-Q_{\text {out }}}{c p *(\rho * V)}\left[\frac{K}{s}\right] \\
Q=A * U * \Delta T[M W]
\end{gathered}
$$

The temperature difference in the heat exchangers is calculated based on equation (1), where $\mathrm{h}$ is used for the hot fluid (flue gasses) and c for the cold fluid (water and steam). Subscripts 1 and 2 indicate inlet and outlet value for the parameter respectively. $Q$ is used for exchanged heat, $A$ is surface of heat exchanger, $U$ is overall heat transfer coefficient and $\mathrm{T}$ is temperature. Using equations (1-3), energy balances of all components of interest are calculated.
The key part of boiler analysis is fuel analysis. This boiler uses a mix of woody fuels.

In regular operation, moisture is analyzed for all incoming shipments of wood to the plant by taking random samples and measuring the moisture content. With this approach, the plant has documented the yearly variation of the moisture, on average per month. Yearly variations of moisture are displayed in Figure 3. Total heat input in the furnace is obtained as a product of lower heating value (LHV) of fuel, calculated using the moisture content reading and the fuel mass flow.

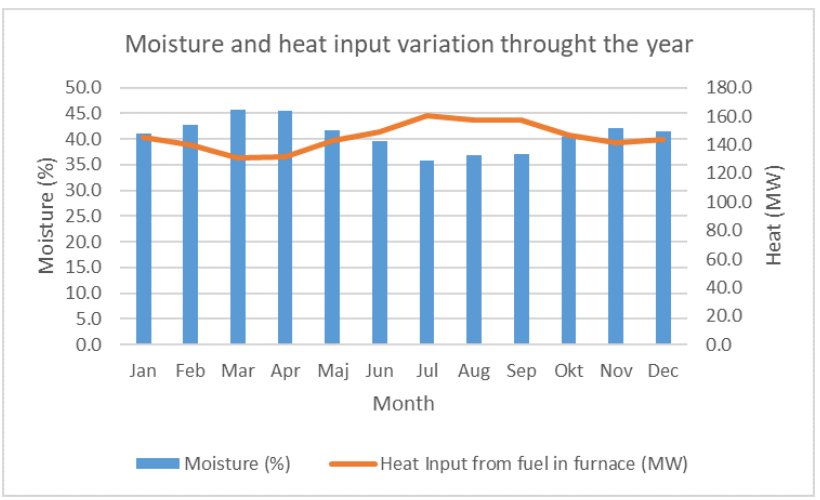

Figure 3. Yearly variation of moisture and heat input

However, this information doesn't allow for analysis with $1 \mathrm{~min}$ sampling time. The moisture content has the highest variation in woody fuels, while the other components of elemental analysis $(\mathrm{C}, \mathrm{H}, \mathrm{O}, \mathrm{N}, \mathrm{S}$ and ash) have minimal variation.

In this work, results from lab analysis of the fuel used in the plant, are used for values of elemental analysis components on dry basis. The moisture content value can be read from the spectra sensor installed online above the conveyor belt. Using the moisture value and fuel conversion equations, we obtain values for fuel composition on wet basis (as received) and use the values to calculate the fuel heating value, hence simulating moisture variations in real-time.

The fuel heating values (LHV and HHV) are calculated by (Saidur et al., 2011):

$$
\begin{gathered}
H H V=0.3491 * X_{C}+1.1783 X_{H} \\
+0.1005 X_{S}-0.0151 * X_{N} \\
-0.1034 * X_{O}-0.0211 \\
* X_{\text {ash }}[M J / k g] \\
L H V=H H V *\left(1-\frac{w}{100}\right)-2.444 * \frac{w}{100} \\
-2.444 * \frac{h}{100} * 8.936 \\
*\left(1-\frac{w}{100}\right)\left[\frac{M J}{k g}\right]
\end{gathered}
$$

where: $\mathrm{X}_{\mathrm{i}}$ is wt.\%. content of the fuel elements on dry basis, $\mathrm{w}$ is moisture content, and $\mathrm{h}$ is hydrogen content. 
Enthalpies and specific heat capacities of the streams are calculated using polynomial functions (Wester, 2015). Other required parameters for the model are obtained from plant documentation (geometry of boiler and capacity of heat exchangers) and tuning parameters are tuned based on historical operational values. The model operates on simplification for full conversion of combustible fuel elements to flue gasses.

In order to capture the dynamics of the process and to have a suitable framework for comparison of the model, key inputs and outputs are identified. These are used during model validation, system identification and control simulations. Key parameters are listed in Table 2. Several key process indicators cannot be obtained from the plant because there are no present sensors for them. There is no measurement signal on fuel mass flow, temperature in the freeboard and mass flow of water sprays in the steam attemperators. Fuel mass flow is estimated based on other related parameters in the energy balance. Due to the lack of measured signals, some common comparisons for boiler performance, such as temperature profile in the furnace are not feasible. Selected outputs for comparison are chosen based on the available sensors: final steam temperature, flue gasses temperature (after superheaters stage), fluidized bed temperature and power output.

Table 2. Key boiler parameters for model

\begin{tabular}{|c|c|}
\hline Inputs & Outputs \\
\hline Fuel mass flow & Power output \\
\hline Water mass flow & Steam final temp. \\
\hline Fuel moisture $(\%)$ & Fluidized bed temp. \\
\hline Air mass flow & Flue gas temp. \\
\hline $\begin{array}{c}\text { Recirc. Flue gas } \\
\text { flow }\end{array}$ \\
\hline
\end{tabular}

The final steam temperature is a key parameter for boiler operation. It is predefined from the manufacturer during construction and it can have small variations from nominal set-point, to ensure safe and efficient operation

Since there is no temperature measurement of the freeboard temperature, the flue gasses temperature after the superheaters section is the first indicator that can be used to assess the operation. This parameter combined with the steam parameters measurements allows to back-calculate the temperatures of the flue gasses at various points.

The fluidized bed temperature is the key parameter that indicates the operation stability for BFB boilers. This parameter has minimal variation, due to its characteristics - dense region with very high thermal capacity.

The power output is key for the control action. Most of the time, the power output is adjusted to satisfy supply and demand for electricity and heat, and controlled change of setpoint is made to achieve it. It is calculated the balance betweenas the energy contained in the steam at the final point (after the last superheater, before turbine inlet) and the starting condition (feedwater tank).

After developing dynamic model for the analyzed plant, the model is tuned and adjusted based on the historical values of the operational parameters. Model validation is done by running developed model with operation data for the key inputs and comparing the output of the model against the operation data. In order to make use of the developed dynamic model for control, it needs to be converted in a suitable form, so that a control structure can work with it. For this work we use linear MPC, developed in Matlab, based on identified linear state-space model.

\subsection{System identification}

State space model is a mathematical form of a system that contains input, output and state variables. Equation 6 shows the form of Discrete-time identified state-space model, identified with n4sid function in Matlab:

$$
\left\{\begin{array}{c}
\dot{x}=A x+B u+K e \\
y=C x+D u+e
\end{array}\right.
$$

where: $x$ is state vector, $\mathrm{y}$ is output vector, $\mathrm{u}$ is input vector, e is disturbance vector, $\mathrm{A}, \mathrm{B}, \mathrm{C}, \mathrm{D}$, and $\mathrm{K}$ are state-space matrices.

Subspace identification is used to identify linear state-space, which will be the basis for the MPC design. Important for the identified model is to have good fit with the output data and to capture process dynamics.

The inputs for the SI process were constituted by step changes in the chosen input signals, with increase and decrease of predefined ratios of 1, 2.5, 5 and $10 \%$. Step signals are combined in a way to capture the impact of coupling inputs on the observed outputs. The input sequence generated for this work contains all combinations of inputs excitation. Inputs and outputs are used from Table 2, only fuel moisture is used as disturbance.

For the defined set of inputs and outputs, a 5th order state space model is identified with n4sid function in Matlab, and it represents the internal model for MPC design and tuning.

\subsection{Control structures}

Model predictive control (MPC) can be defined as class of control algorithms that utilizes an explicit process model to predict the future response of a plant (Qin and Badgewell, 2013). MPC uses a dynamic model of the plant to predict future actions of the manipulated variables on the plant output. MPC is defined with: process model, set of constraints and objective function. The function that describes the MPC can be found in literature under the names of objective, target or cost 
function. This function provides information about the importance given to control error minimization and frequency of actuators operation. The process model should capture the dynamics of inputs, outputs and disturbances in the controlled process. The drawback is that MPC is more complex to develop compared to conventional PI control, and it requires more time to develop and tune properly.

PI (Proportional and Integral) Control is a commonly applied control structure in industry. It combines the benefits of proportional and integral control into one. PI scheme is presented in Figure 4. The PI controller does not receive signal about the disturbance in the system.

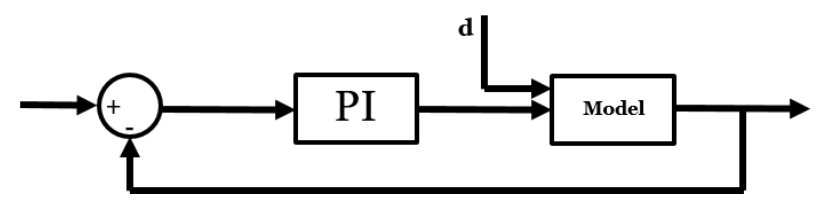

Figure 4. PI Control Scheme

A commonly used equation for PI controller is:

$$
p(t)=\bar{p}+K_{c}\left(e(t)+\frac{1}{\tau_{I}} \int_{0}^{t} e\left(t^{*}\right) d t^{*}\right)
$$

where $p(t)$ is the controller output, $\mathrm{K}_{\mathrm{c}}$ is the proportional gain, $\mathrm{e}(\mathrm{t})$ is the measured error between output signal and setpoint, $\tau_{I}$ is the integral time.

The three PI controllers were tuned using an internal model control method and the control parameters were successively fine-tuned to improve the performance (Tan et al., 2006). For a full comparison, the PIs were integrated with feed-forward (FF) for disturbance rejection for case 2 . The FF model was set as a first order input-output model according to equation 6 .

$$
p_{F F}=-d \cdot \frac{G_{d}}{G_{p}}
$$

Where $p_{F F}$ is added to the PI output, $\mathrm{d}$ is the disturbance signal, and $\mathrm{Gd}$ and $\mathrm{Gp}$ are first-order transfer functions between $\mathrm{d}$ and $\mathrm{y}$ (process output), and $\mathrm{p}$ and $\mathrm{y}$ respectively. FF PI scheme is presented in Figure 5. The disturbance signal is added to the PI controller as FF.

The control parameters used for the PI control in both configurations is provided in Table 3 . This table also contains information about the connection between inputs and outputs in the PI logics i.e. which input is manipulated to control a specified output.

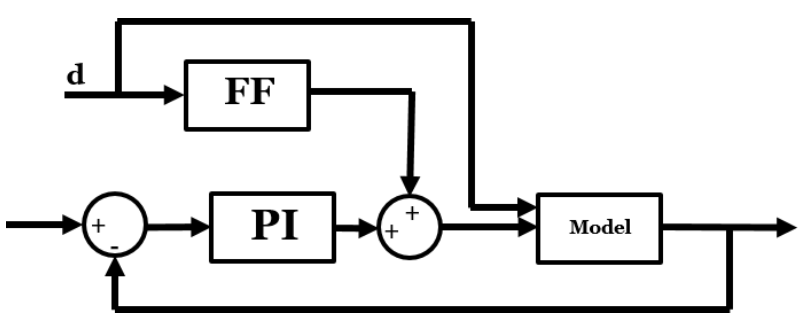

Figure 5. FF PI Control Scheme

The PI structure contains 3 SISO (Single Input Single Output) control loops, listed in Table 3.

Table 3. PI controller parameters

\begin{tabular}{|c|c|c|}
\hline Control loop & Proportional $\boldsymbol{K}_{\boldsymbol{c}}$ & Integral $\boldsymbol{\tau}_{\boldsymbol{I}}$ \\
\hline $\begin{array}{c}\text { Fuel mass flow } \\
\text { Power Output }\end{array}$ & $0.4(-)$ & $150(\mathrm{~s})$ \\
\hline $\begin{array}{c}\text { Water mass flow } \\
\text { Final Steam temp. }\end{array}$ & $-0.55(-)$ & $600(\mathrm{~s})$ \\
\hline $\begin{array}{c}\text { Total air mass flow } \\
\text { Fluidized bed temp. }\end{array}$ & $-0.5(-)$ & $1500(\mathrm{~s})$ \\
\hline
\end{tabular}

After importing the identified model in the MPC Toolbox in Matlab, its parameters are defined. Nominal values for the input and outputs are set, constraints on the inputs range and rate of change are set. Key MPC parameters used are provided in Table 4, while the constraints used for all controllers are listed in Table 5.

Table 4. MPC parameters

\begin{tabular}{|c|c|}
\hline MPC Parameter & Value \\
\hline Sampling time & $60(\mathrm{~s})$ \\
\hline Prediction horizon & 10 \\
\hline Control horizon & 2 \\
\hline
\end{tabular}

The error between future outputs and target values is minimized by means of a quadratic objective function, presented in Equation 9:

$$
\begin{aligned}
J=W_{j}^{e_{y}} S_{e_{y}}(k)^{2} & +W_{j}^{M V} S_{M V}(k)^{2} \\
& +W_{j}^{\Delta M V} S_{\Delta M V}(k)^{2}
\end{aligned}
$$

The three terms in the objective function refer to the output error $e_{y}$ (between controlled variables and targets), the manipulated variables (MV), and the change rate of manipulated variables. The weights $W j$ penalize each term in a different way.

Table 5. Constraints on manipulated parameters

\begin{tabular}{|c|c|c|}
\hline Input & $\begin{array}{c}\text { Nominal value } \\
(\mathrm{kg} / \mathrm{s})\end{array}$ & $\begin{array}{c}\text { Control range } \\
\text { constraints (kg/s) }\end{array}$ \\
\hline Fuel flow & 13.7 & $6-16$ \\
\hline Water flow & 35 & $20-40$ \\
\hline Air flow & 50 & $40-60$ \\
\hline
\end{tabular}


MPC control scheme is presented in Figure 6. The MPC controller does not receive signal about the measured disturbance in the system.

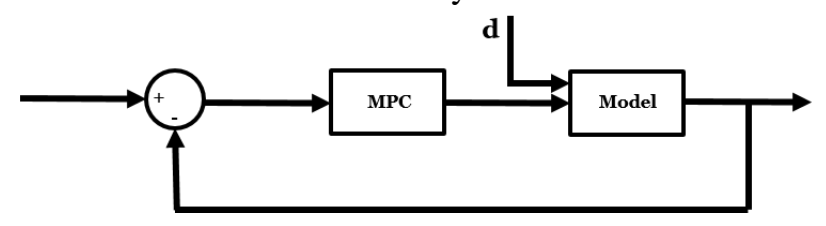

Figure 6. MPC Control Scheme

FF MPC control scheme is presented in Figure 7. The disturbance signal is added to the MPC controller as FF.

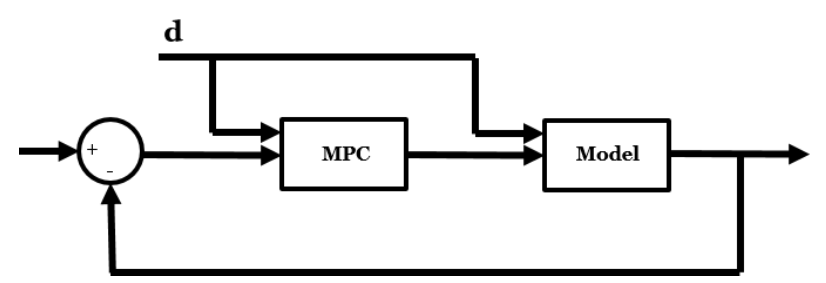

Figure 7. MPC FF Control Scheme

\section{Results}

After developing the control structures, they are compared in various scenarios, for their capability to deal with system disturbances and set points change. The moisture content (\%) in the fuel is the system disturbance. Four types of controllers are compared-PI, FF PI, MPC and FF MPC. A list of scenarios, description of changes made in each setpoint and disturbance signal is provided in Table 6 .

The controllers are analyzed in these scenarios for control and statistical metrics. Control metrics are overshoot, rise and settling times, which are common indices for evaluating controller performance, while statistical metrics used are the mean absolute error and standard deviation. Control metrics are chosen as standard control performance test, while statistical metrics can show us how much variation in controlled outputs we can expect during control scenarios and control actions. Since in scenario 3 we analyze the performance of controller to keep constant setpoint rather than response to step change, in this scenario we provide only statistical metrics.

The overshoot values for Scenarios 1 and 2 are displayed in Table 7 . The values are expressed in $\%$ of the new set point and represent the height of the first peak after crossing the new setpoint value.

Rise time is defined as the time required for the output to change from $10 \%$ to $90 \%$ from the initial to the new setpoint.

Settling time is considered as the time required to reach $2 \%$ error between the signal and the new setpoint value.
Since settling and rise time are related to the change of setpoint, they are analyzed only for scenarios 1 and 2 . Settling and rise times are shown in Tables 8 and 9 respectively. Due to limited space, statistical indicators and plots of inputs and outputs are shown only for Scenario 3. Absolute mean error is shown in Table 10, while standard deviation is in Table 11. Inputs are plotted in Figure 8, while outputs are plotted in Figure 9.

The simulations are done towards assessing the capability of the 4 controllers to deal with different control scenarios. Results are reported on 60s sampling time. It can be noted that results differ in the scenarios and the criteria for evaluation. This shows that we can't label one control option as absolutely best rather the best one for a specific application or in testing scenario.

It has to be noted that no weights are added in MPC tuning during this work to favorize one input or output on the expense of the rest. Adding weights on the inputs and the outputs would cause the controller to put more effort towards one parameter than the others and would make the comparison uneven.

Scenario 3 is the closest to real operation control actions. The disturbances are frequent during operation, and they come with different magnitudes due to the random uniform signal block used in Simulink. This signal is generated with sampling time of $50 \mathrm{~min}$. It can be said that Scenario 3 is solid basis towards more demanding control actions analysis.

Overshoots analysis shows that the lowest overshoot for all controllers is in output 3 - fluidized bed temperature, due to the huge thermal inertia of this region and slow changes.

On the settling time analysis, it takes the longest time to settle to the specified new setpoint, which is to be expected due to the same characteristic that makes the minimal or no overshoot.

From the results of scenario 3, we can observe that in statistical parameters, controllers with FF show better performance compared to the ones without FF - lower error and deviation. MPC FF has the lowest error and deviation in this Scenario. In all 3 scenarios, PI control has the worst control on output 3 - temperature of fluidized bed. Except for this parameter, we can see that for the other parameters the difference between MPC and PI controllers is not big. 
Table 6. Analyzed Control scenarios

\begin{tabular}{|c|c|c|c|c|}
\hline Scenario & $\begin{array}{l}\text { Steam temp. } \\
\text { setpoint }[C]\end{array}$ & $\begin{array}{c}\text { Power setpoint } \\
{[\mathrm{MW}]}\end{array}$ & $\begin{array}{c}\text { Fluid. Bed setpoint } \\
{[\mathrm{C}]}\end{array}$ & $\begin{array}{c}\text { Moisture disturbance } \\
{[\%]}\end{array}$ \\
\hline 1 & $\begin{array}{c}\text { Step: } 535-520 \\
\text { constant } \\
\text { constant }\end{array}$ & $\begin{array}{c}\text { constant } \\
\text { Step: } 110-100 \\
\text { constant }\end{array}$ & $\begin{array}{c}\text { constant } \\
\text { constant } \\
\text { Step: } 910-900\end{array}$ & $\begin{array}{l}\text { constant } \\
\text { constant } \\
\text { constant }\end{array}$ \\
\hline 2 & $\begin{array}{c}\text { Step: } 535-520 \\
\text { constant } \\
\text { constant }\end{array}$ & $\begin{array}{c}\text { constant } \\
\text { Step: } 110-100 \\
\text { constant }\end{array}$ & $\begin{array}{c}\text { constant } \\
\text { constant } \\
\text { Step: } 910-900\end{array}$ & $\begin{array}{l}\text { Step: } 48-53 \\
\text { Step: } 48-53 \\
\text { Step: } 48-53\end{array}$ \\
\hline 3 & constant & constant & constant & Random uniform input \\
\hline
\end{tabular}

Table 7. Overshoot $(\%)$

\begin{tabular}{|c|c|c|c|c|c|c|}
\hline Scenario & \multicolumn{3}{|c|}{ Scenario 1 } & \multicolumn{3}{c|}{ Scenario 2 } \\
\hline Controller & Steam temp. & Power & FB. temp. & Steam temp. & Power & FB. temp. \\
\hline 1. PI & 0 & 0.04 & 0 & 3.4 & 1 & 0.8 \\
\hline 2. FF PI & 0 & 0.04 & 0 & 1.1 & 0.04 & 0.7 \\
\hline 3. MPC & 0.17 & 0.2 & 0 & 0.82 & 2.6 & 0.4 \\
\hline 4. FF MPC & 0 & 0.3 & 0 & 0.16 & 0.67 & 0.1 \\
\hline
\end{tabular}

Table 8. Settling time (s)

\begin{tabular}{|c|c|c|c|c|c|c|}
\hline Scenario & \multicolumn{3}{|c|}{ Scenario 1 } & \multicolumn{3}{c|}{ Scenario 2 } \\
\hline Controller & Steam temp. & Power & FB. temp. & Steam temp. & Power & FB. temp. \\
\hline 1. PI & 720 & 1080 & 4620 & 1680 & 540 & 8640 \\
\hline 2. FF PI & 720 & 1080 & 4620 & 2340 & 840 & 8340 \\
\hline 3. MPC & 480 & 600 & 1680 & 3720 & 1680 & 4380 \\
\hline 4. FF MPC & 1320 & 540 & 960 & 1680 & 1380 & 3900 \\
\hline
\end{tabular}

Table 9. Rise time (s)

\begin{tabular}{|c|c|c|c|c|c|c|}
\hline Scenario & \multicolumn{3}{|c|}{ Scenario 1 } & \multicolumn{3}{c|}{ Scenario 2 } \\
\hline Controller & Steam temp. & Power & FB. temp. & Steam temp. & Power & FB. temp. \\
\hline 1. PI & 180 & 180 & 2220 & 120 & 120 & 300 \\
\hline 2. FF PI & 180 & 180 & 2160 & 180 & 180 & 360 \\
\hline 3. MPC & 420 & 120 & 180 & 120 & 120 & 120 \\
\hline 4. FF MPC & 720 & 240 & 660 & 180 & 180 & 420 \\
\hline
\end{tabular}

Table 10. Mean absolute error (-) for Scenario 3

\begin{tabular}{|c|c|c|c|}
\hline Controller & Steam temp. & Power output & Fluidized bed temp. \\
\hline 1. PI & 0.0648 & 0.0523 & 0.7130 \\
\hline 2. FF PI & 0.1601 & 0.0196 & 0.6885 \\
\hline 3. MPC & 0.3566 & 0.0644 & 0.2237 \\
\hline 4. FF MPC & 0.0407 & 0.0079 & 0.0513 \\
\hline
\end{tabular}

Table 11. Standard deviation (-) for Scenario 3

\begin{tabular}{|c|c|c|c|}
\hline Controller & Steam temp. & Power output & Fluidized bed temp. \\
\hline 1. PI & 0.1476 & 0.1449 & 0.8622 \\
\hline 2. FF PI & 0.2322 & 0.0584 & 0.8364 \\
\hline 3. MPC & 0.6253 & 0.1390 & 0.2886 \\
\hline 4. FF MPC & 0.0643 & 0.0178 & 0.0618 \\
\hline
\end{tabular}



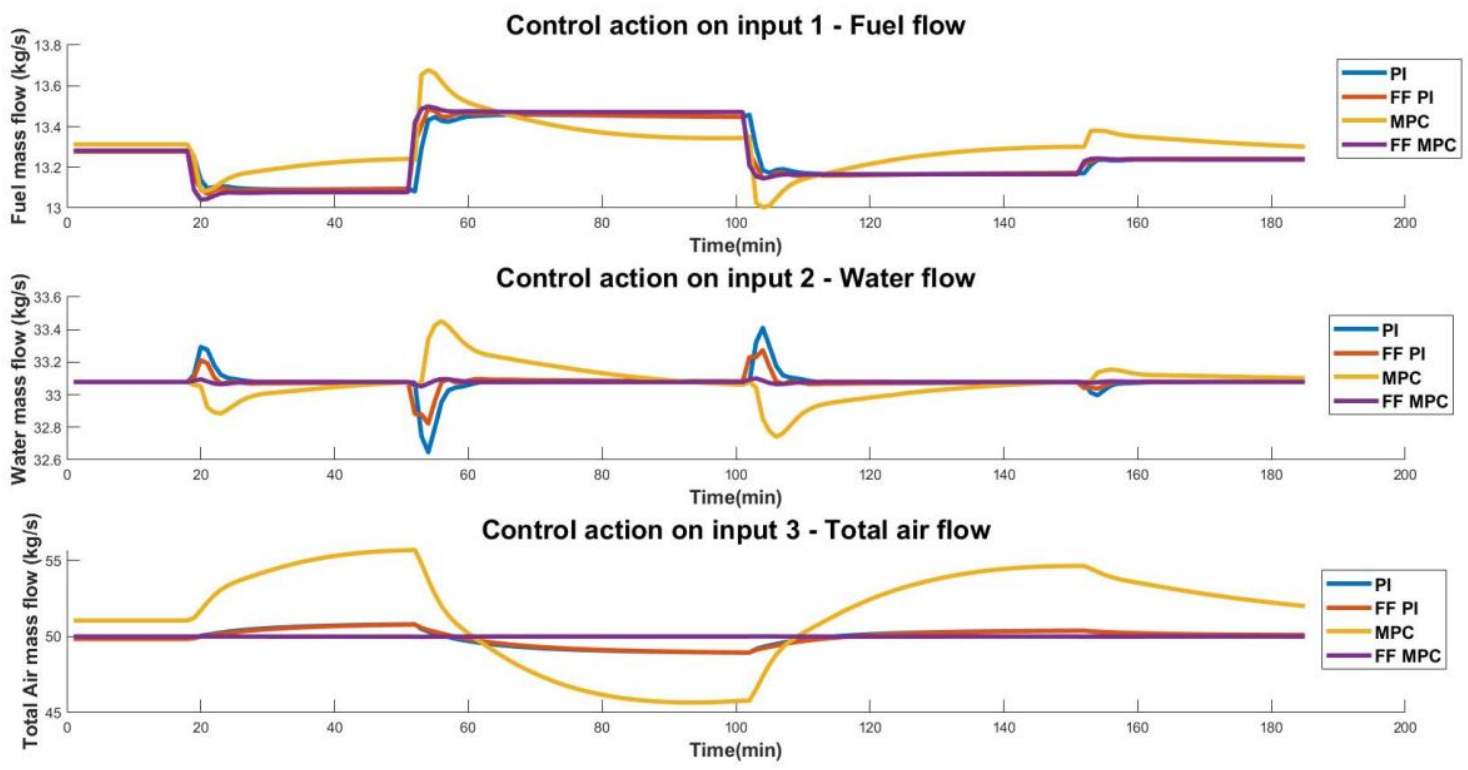

Figure 8. Control action on Inputs in Scenario 3

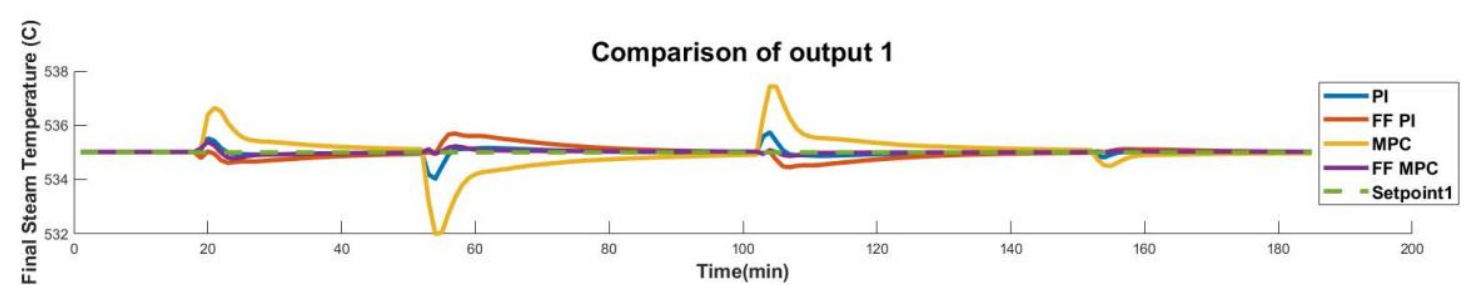

Comparison of output 2
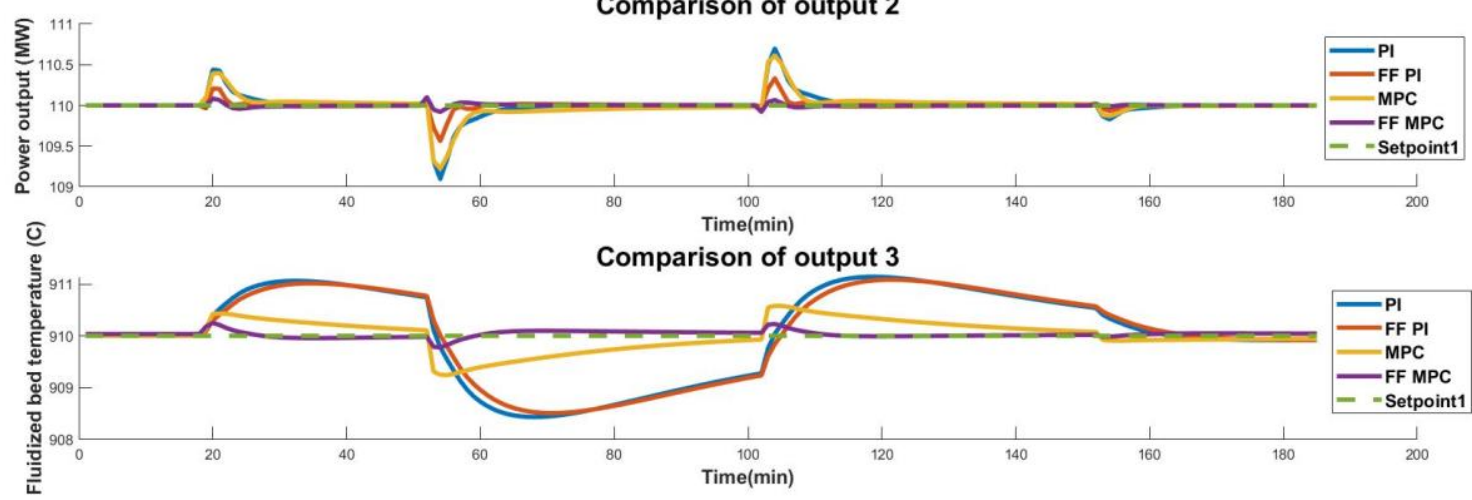

Figure 9. Control action on inputs in Scenario 3 


\section{Conclusions}

Four different control strategies were implemented on a dynamic boiler model and compared, based on control and statistical metrics. It was shown that adding feedforward signal about the fuel moisture, improves the control parameters for both PI and MPC control. By most analyzed parameters FF MPC shows the best performance.

PI FF control provide better results than MPC for the outputs which can be controlled with 1 input manipulation. For the output that depends on most inputs (fluidized bed temperature), MPC show better control results. This shows the limitation of PI control.

FF MPC with accurate characterization of the fuel moisture can help towards dealing with the disturbances in the plant caused by fuel characteristics variation.

Future work is aimed towards exploring the capabilities of MPC with more operation realistic scenarios. Change of power output based on documented operational data, introduce performance deterioration and constraints set based on actuators properties are some of the planned features to be added.

\section{Acknowledgements}

This work is done under DYNOP (Dynamic Optimization) research project, funded by Swedish Knowledge Foundation (KKS). Thanks to the support from the ESEM staff, especially towards Per Orvind for supplying us with all the required information.

\section{References}

U. Arena, R. Chirone, M. D'Amore, M. Miccio, and P. Salatino. Some Issues in Modelling Bubbling and Circulating Fluidized-Bed Coal Combustors. Powder Technology, 82(3): 301-16, 1995.

K. Atsonios, A. Nesiadis, N. Detsios, K. Koutita, N. Nikolopoulos, and P. Grammelis. Review on Dynamic Process Modeling of Gasification Based Biorefineries and Bio-Based Heat \& Power Plants. Fuel Processing Technology, 197: $1061-88, \quad 2020$ https://doi.org/10.1016/j.fuproc.2019.106188.

K. J. Åström and R. D. Bell. Drum-Boiler Dynamics. Automatica, 36: 363-378, 2000.

D. S. Carrasco and G. C. Goodwin. Feedforward Model Predictive Control. Annual Reviews in Control, 35(2): 199206,

2011. http://dx.doi.org/10.1016/j.arcontrol.2011.10.007.

F. Casella, J. G. van Putten, and P. Colonna 2014. DYNAMIC SIMULATION OF A BIOMASS-FIRED STEAM POWER PLANT: A COMPARISON BETWEEN CAUSAL AND A-CAUSAL MODULAR MODELING, In Proceedings - IMECE2007,2007 ASME International Mechanical Engineering Congress and Exposition November 11-15, 2007, Seattle, Washington, USA, pages 205-216, 2007.

A. Galgano, P. Salatino, S. Crescitelli, F. Scala, and P. L. Maffettone. A Model of the Dynamics of a Fluidized Bed
Combustor Burning Biomass. Combustion and Flame, 140(4): 371-84, 2005

M. Huttunen, J. Peltola, S. Kallio, L. Karvonen, T. Niemi, and V. Y. Outinen. Analysis of the Processes in Fluidized Bed Boiler Furnaces during Load Changes. Energy Procedia, 120: $\quad 580-87, \quad 2017$. http://dx.doi.org/10.1016/j.egypro.2017.07.175.

B. Leckner. Fluidized Bed Combustion Research and Development in Sweden: A Historical Survey. Thermal Science, 7(2): 3-16, 2003.

A. Peña. Bubbling Fluidized Bed (BFB) When to Use This Technology?. In Proceedings - IFSA 2011, Industrial Fluidization, November 2011 South Africa, pages 1-12, 2011.

J. S. Qin and T. A. Badgwell. A Survey of Industrial Model Predictive Control Technology. Control Engineering Practice, 11: 733-64, 2003.

S. Ravelli, A. Perdichizzi, and G. Barigozzi. Description, Applications and Numerical Modelling of Bubbling Fluidized Bed Combustion in Waste-to-Energy Plants. Progress in Energy and Combustion Science, 34(2): 22453, 2008.

R. Saidur, E. A. Abdelaziz, A. Demirbas, M. S. Hossain, and S. Mekhilef. A Review on Biomass as a Fuel for Boilers. Renewable and Sustainable Energy Reviews, 15(5): 226289, 2011. http://dx.doi.org/10.1016/j.rser.2011.02.015.

J. Sandberg, R. B. Fdhila, E. Dahlquist, and A. Avelin. Dynamic Simulation of Fouling in a Circulating Fluidized Biomass-Fired Boiler. Applied Energy, 88(5): 1813-24, 2011. http://dx.doi.org/10.1016/j.apenergy.2010.12.006.

F. Scala and R. Chirone. Fluidized Bed Combustion of Alternative Solid Fuels. Experimental Thermal and Fluid Science, 28(7): 691-99, 2004.

P. Szentannai. Modern Power Plant Control for Energy Conservation, Efficiency Increase, and Financial Benefit. In Wei-Yin Chen, Toshio Suzuki and Maximilian Lackner, editors, Handbook of Climate Change Mitigation and Adaptation, pages 1-20, 2015. ISBN 978-1-4614-6431-0, doi: 10.1007/978-1-4614-6431-0_22-2

P. Szentannai. Mathematical Modeling and Model-Based Optimum Control of Circulating Fluidized Bed Combustors. Periodica Polytechnica Civil Engineering, 55(1): 3-11, 2011.

W. Tan, J. Liu, T. Chen, and H. J. Marquez. Comparison of Some Well-Known PID Tuning Formulas. Computers and Chemical Engineering, 30(9): 1416-23, 2006.

L. Wester. Tables and diagrams for energy technical calculations, Marklund Solutions, Sweden, 2015.

N. Zimmerman, K. Kyprianidis, and C. F. Lindberg. Waste Fuel Combustion: Dynamic Modeling and Control. Processes, 6(11): 1-19, 2018. 